\title{
AÇÕES AFIRMATIVAS DE PROMOÇÃO DA IGUALDADE RACIAL NA EDUCAÇÃO: LUTAS, CONQUISTAS E DESAFIOS
}

\author{
Nilma Lino Gomes ${ }^{1}$ \\ Paulo Vinícius Baptista da Silva ${ }^{2}$ \\ José Eustáquio DE BRITO³
}

\begin{abstract}
RESUMO: As ações afirmativas de promoção da igualdade racial ressignificaram a luta pelo direito à educação no Brasil. A entrada de sujeitos pertencentes a coletivos diversos e historicamente tratados como desiguais no ensino superior, a presença de pessoas negras nos concursos públicos da administração federal por meio da implementação das cotas raciais, as várias iniciativas de ensino de história e cultura afro-brasileira e africana nas escolas da Educação Básica, bem como os direitos garantidos no Estatuto da Igualdade Racial, têm feito emergir diversos conhecimentos e experiências produzidos pelos sujeitos negros nas suas vivências políticas, sociais e culturais. Tudo isso tem transformado a ciência, a educação e a sociedade.
\end{abstract}

Palavras-chave: Ações Afirmativas. Educação. Igualdade Racial. Cotas Raciais. Política Educacional.

\section{AFFIRMATIVE ACTION FOR THE PROMOTION OF RACIAL EQUALITY IN EDUCATION: STRUGGLES, ACHIEVEMENTS AND CHALLENGES}

\begin{abstract}
Affirmative action to promote racial equality has resigned the struggle for the right to education in Brazil. The entry of subjects belonging to diverse groups and historically treated as unequal in higher education, the presence of black people in public competitions of the federal administration through the implementation of racial quotas, the various initiatives for teaching African and Afro-Brazilian history and culture in elementary schools, as well as the rights guaranteed in the Statute of Racial Equality, have brought out diverse knowledge and experiences produced by black people in their political, social, and cultural experiences. All this has transformed science, education and society.
\end{abstract}

Keywords: Affirmative Action. Education. Racial Equality. Racial Quotas. Educational Policy.

\footnotetext{
1.Universidade Federal de Minas Gerais - Universidade Federal de Minas Gerais - Faculdade de Educação - Departamento de Administração Escolar - Belo Horizonte (MG), Brasil. E-mail: nilmalinogomes@gmail.com

2.Universidade Federal do Paraná - Setor de Educação - Departamento da Teoria e Fundamentos da Educação - Curitiba (PR), Brasil. E-mail: pauloviniciusufpr@gmail.com

3.Universidade do Estado de Minas Gerais - Faculdade de Educação - Belo Horizonte (MG), Brasil. E-mail: joseeustaquio.brito@uemg.br Editor de Seção: Salomão Barros Ximenes
} 


\section{ACCIONES AFIRMATIVAS PARA LA PROMOCIÓN DE LA IGUALDAD RACIAL EN LA EDUCACIÓN: LUCHAS, LOGROS Y DESAFÍOS}

RESUMEN: La acción afirmativa para promover la igualdad racial ha dado un nuevo significado a la lucha por el derecho a la educación en Brasil. El ingreso de sujetos pertenecientes a diversos grupos e históricamente tratados como desiguales en la educación superior, la presencia de personas negras en los concursos públicos de la administración federal a través de la implementación de cuotas raciales, las diversas iniciativas de enseñanza de la historia y la cultura africana y afrobrasileña en las escuelas de educación básica, así como los derechos garantizados en el Estatuto de la Igualdad Racial, han hecho emerger diversos conocimientos y experiencias producidas por las personas negras en sus vivencias políticas, sociales y culturales. Todo ello ha transformado la ciencia, la educación y la sociedad.

Palabras clave: Acción Afirmativa. Educación. Igualdad Racial. Cuotas Raciales. Política Educativa.

A tese desenvolvida por GOMES (2017) de que o movimento negro é um educador da sociedade e do Estado brasileiros no que se refere à compreensão do fenômeno do racismo e dos caminhos para combatê-lo é o que orienta a nossa reflexão sobre as ações afirmativas de promoção da igualdade racial na educação.

A tese defendida pela autora de que os saberes construídos pela população negra ao longo da sua trajetória social, cultural, política e nas lutas antirracistas são organizados e sistematizados pelo movimento negro, o qual também atua como um produtor de saberes, ajuda-nos a entender a trajetória histórica e política de várias reivindicações desse movimento social, ao longo do século $\mathrm{XX}$, algumas das quais surgiram como protesto e denúncia e alcançaram o status de políticas públicas no século XXI.

Embora a trajetória da população negra organizada na luta por direitos e pelo direito às ações afirmativas já tenha sido foco de reflexões de uma literatura especializada (DOMINGUES, 2005; 2007; 2008; GOMES, 2017; LIMA, 2010; MARÇAL, 2016; PEREIRA, 2008; PINHO, 2003; SILVA; BORBA, 2018; SILVÉRIO, 2002, entre outros) não há como falar sobre o tema sem nos reportarmos a uma digressão histórica, mesmo que breve, para reforçar a afirmação de que essas políticas não existiriam, em nosso país, se não fosse a força reivindicativa, propositiva e o perfil político educador do movimento negro. Consideramos que esse movimento social é o principal responsável pela adoção das políticas de ações afirmativas de promoção da igualdade racial na educação. ${ }^{1}$

A reivindicação por uma educação democrática, como uma das estratégias de combate ao racismo, sempre foi um dos temas centrais das lutas do movimento negro do passado e do presente. Podemos observar como ela comparece nas pautas das várias organizações negras do século XX, sempre acompanhada da denúncia de que as pessoas negras não acessavam a Educação Básica como um direito, de que a maioria das crianças negras não estava presente na escola básica e, quando conseguiam cursá-la, era sempre em situação de desvantagem quando comparadas com as brancas. Fazia parte dessas reivindicações, também, a constatação de que a juventude negra sequer colocava a Educação Superior no seu horizonte como possibilidade de estudo e de formação.

O protagonismo do Movimento Negro brasileiro ao reivindicar do Estado brasileiro e da sociedade políticas específicas de combate às desigualdades raciais tem sido apresentado por pesquisas que abordam as condições de vida da população brasileira, como destaca o fragmento abaixo: 
[...] quando se trata de refletir sobre o desenho de alternativas, é preciso considerar o papel ativo e legítimo desempenhado pelos mais diversos movimentos sociais, com base em seus mecanismos de mobilização e pressão sobre o poder público e a sociedade, de modo a reconhecer a legitimidade de suas ações no sentido de reorientar as prioridades políticas e orçamentárias do Estado. Ou seja, não se pode pensar os efeitos redistributivos do "capital social gerado pelo Estado" sem considerar que esse capital se constrói a partir do reconhecimento e do respeito às reivindicações dos movimentos sociais enquanto atores políticos. (BRITO, 2011, p. 121)

A ação do movimento negro, não só no combate ao racismo, mas também na proposição política de alternativas para a correção das desigualdades raciais, vivenciou uma trajetória histórica de amadurecimento político ao longo do século XX. As organizações negras constituídas a partir do início desse século inspiraram-se no legado de resistência negra deixado pelos africanos e africanas escravizados e seus descendentes. Além de uma experiência interna de lutas contra a escravidão, a opressão e o racismo no decorrer do processo histórico brasileiro, essas organizações também se inspiraram em referências internacionais, tais como o movimento pelos direitos civis dos negros norte-americanos, nos anos 1950 e 1960, as lutas de libertação e os processos de descolonização dos países africanos de língua oficial portuguesa, nos anos 1960 e 1970, e a articulação internacional pelo fim do regime do Apartheid (1948 a 1994), na África do Sul.

No que refere à tomada de consciência acerca da relevância da Educação Superior como um espaço importante para a população negra, é possível perceber que desde a Convenção Nacional do Negro Brasileiro, organizada pelo Teatro Experimental do Negro, a sinalização da necessidade de inserção de negras e negros na Educação Superior se fazia presente. Com duas reuniões, em 1945 em São Paulo e 1946 no Rio de Janeiro, a Convenção apresentou, em suas conclusões, um "Manifesto à Nação Brasileira" no qual, entre diversas propostas de políticas antirracistas, já demandava vagas e bolsas para negros e negras no ensino superior. Todas as propostas do Manifesto foram publicadas, entre 1948 e 1950, no jornal dessa organização negra intitulado O Quilombo (NASCIMENTO, 2003).

No período da ditadura militar (1964-1985), o regime ditatorial coibiu, perseguiu e proibiu os temas das desigualdades sociais e raciais. O discurso público era amplamente controlado pelo regime e foi marcado pela ausência de antagonismo e de crítica, orientado que estava pela defesa da ditadura militar e do conservadorismo na política e nos costumes. Esse período acentuou a hegemonia do mito da democracia racial como forma de interpretação do Brasil, e discursos divergentes eram carimbados como antipatriotas e causadores de divisionismo.

Embora nem sempre a ação do movimento negro na insurgência contra a ditadura militar tem sido destacada pela literatura das ciências sociais brasileiras, é importante enfatizar a sua presença. Compreendê-la é também reconhecer que a luta antirracista desencadeada pelo movimento negro sempre se fez presente juntamente com o conjunto das reivindicações políticas das demais organizações emancipatórias da sociedade civil em prol da democracia. Ou seja, não há tendência ao sectarismo ou a formação de "guetos negros" nas lutas antirracistas desenvolvidas pelo movimento negro. Pelo contrário, há a compreensão de que, no Brasil, a democracia sem a pauta racial é politicamente frágil. Ou seja, sem democracia não há igualdade racial e sem igualdade racial não há democracia.

As ações das várias entidades do movimento negro na luta contra a ditadura podem ser constatadas na afirmação de PINHO:

Durante o regime militar inaugurado com o golpe de 31 de março de 1964 diversos grupos se organizaram em todo o país. No Rio Grande do Sul, o já citado Grupo Palmares. No segregado interior de São Paulo assistiu-se uma intensa movimentação com o grupo Evolução de Campinas 
fundado por Thereza Santos e Eduardo Oliveira e Oliveira em 1971 e o Festival Comunitário Negro Zumbi (FECONEZU) que existe desde 1978 até os dias de hoje. Na capital paulista o Instituto de Pesquisas e Estudos Afro-Brasileiros (IPEAFRO) fundando por Abdias do Nascimento em 1980 no seu retorno do exílio. No Rio de Janeiro o Instituto de Pesquisa de Cultura Negra (IPCN) e a Sociedade de Estudo de Cultura Negra no Brasil (SECNEB), A Sociedade de Intercâmbio Brasil África (SINBA), o Grupo de Estudos André Rebouças, etc. Na Bahia o Núcleo Cultural Afro-Brasileiro, o Grupo de Teatro Palmares Iñaron e assim por diante (2003, p. 6).

No período de abertura democrática, no final da década de 1970 e início dos anos 1980, ocorreu a reorganização do movimento negro. $\mathrm{O}$ foco principal das reivindicações negras desse período foi o desmonte da narrativa da democracia racial que negava o racismo presente na sociedade brasileira. Nesse contexto, a luta pelo reconhecimento do racismo, no país, tornou-se o alvo principal. A pauta de denúncia ao racismo e as reivindicações por educação mantiveram seu grau de importância, com o acesso à educação escolar pública considerado uma vital forma de buscar igualdade e possibilidade de mobilidade social para negros e negras. Foram marcas permanentes nessas demandas, o acesso a oportunidades educacionais na Educação Básica e a participação mais efetiva de jovens negros no ensino superior.

No final da década de 1980 e na primeira metade dos anos 1990 a luta do movimento negro pelo reconhecimento do racismo como um fenômeno que estrutura as relações sociais e raciais, no Brasil, continuou muito ativa. Ela foi sendo, aos poucos, aprimorada e as propostas de políticas de promoção de igualdade na educação começam a se tornar mais densas e públicas. Essa pauta foi fortalecida em diversos eventos: no centenário da abolição em 1988; em paralelo, 1987-1988, na Assembleia Nacional Constituinte; nas discussões e propostas para a Lei de Diretrizes e Bases da Educação entre 1988 e 1996; na Marcha Zumbi dos Palmares Contra o Racismo, pela Cidadania e pela Vida, em 1995.

A Marcha Zumbi dos Palmares apresentou ao então Presidente, um documento composto por três partes; "Introdução" com críticas ao mito da democracia racial; "Diagnóstico" que aponta avanços (legais e institucionais), bem como a persistência de práticas racistas; e um "Programa de superação do racismo e da desigualdade racial", contendo propostas para diversas áreas. No que diz respeito à educação, entre o conjunto de propostas constavam o desenvolvimento de ações afirmativas para o acesso à universidade e a implementação de cursos profissionalizantes.

A resposta do governo federal à Marcha Zumbi dos Palmares gerou a manifestação da Presidência da República, reconhecendo que o Brasil é um país onde o racismo se faz presente e está arraigado. Aqui o exemplo é bastante revelador: ao ser indagado pelo movimento negro, o governo brasileiro deu uma resposta que foi vital para os desdobramentos posteriores, ou seja, o reconhecimento público do Estado brasileiro de que o racismo está presente na estrutura do nosso país e, portanto, o governo deveria desenvolver políticas públicas para enfrentá-lo.

Consideramos que, após a aprovação de dois pontos vitais na Constituição Federal de 1988, o artigo $5^{\circ}$, inciso XLII, o qual afirma que o racismo é crime inafiançável e imprescritível e o artigo 68 nas Disposições Constitucionais Transitórias que dispõe sobre o reconhecimento e a titulação das terras dos remanescentes de quilombos (BRASIL, 1988), o reconhecimento público feito pela Presidência da República, no contexto da Marcha Zumbi dos Palmares, em 1995, assumindo a existência do racismo no Brasil, foi um passo decisivo para pavimentar as reivindicações por políticas de ações afirmativas para a população negra desencadeadas nos anos posteriores até se tornarem um dos eixos centrais das políticas de igualdade racial implementadas a partir dos anos 2000 .

Um dos resultados da Marcha Zumbi dos Palmares, em 1995, foi o decreto presidencial de 20 de novembro de 1995, que instituiu o Grupo de Trabalho Interministerial (GTI) com o objetivo de promover políticas para a "valorização da população negra". O GTI, composto por militantes negros e negras e 
representantes do governo federal, desenvolveu atividades entre 1995 e 1997 . Na sua atuação, reproduziu no interior do governo federal experiências de conselhos formados por membros de governo e ativistas de movimentos sociais que já haviam sido colocadas em prática em alguns municípios e estados brasileiros, gerando resultados em políticas locais e estaduais para a população negra.

A Fundação Cultural Palmares, criada como órgão vinculado ao Ministério da Cultura em 1988, e resultado das reivindicações e denúncias do movimento negro por ocasião dos 100 anos da Abolição, em 1988, também pode ser considerada uma iniciativa importante que pavimentou o caminho das políticas de ações afirmativas no Brasil. A Fundação, quando criada, tinha objetivo de "promover a preservação dos valores culturais, sociais e econômicos da influência negra na Formação da sociedade Brasileira” (BRASIL, 1988). Seu surgimento vem marcado com os ares de redemocratização na "Nova República" e teve como objetivo também a identificação e o reconhecimento das comunidades remanescentes de quilombos. Sua atuação nos anos 1990 foi crescente e, nesse espaço, encontravam-se alguma interlocução e apoio a pautas dos movimentos sociais.

Foram muito significativas, entre 1998 e 2000, as reuniões preparatórias para a participação do Brasil na III Conferência Mundial Contra o Racismo, Discriminação Racial, Xenofobia e Intolerâncias Correlatas, no ano de 2001, em Durban, na África do Sul. Consideramos essa ação como um passo muito importante na caminhada social e política do movimento negro e suas pressões sobre o Estado brasileiro em prol da implementação das ações afirmativas. Na Declaração e no Plano de Ação de Durban, as propostas de políticas afirmativas para a universidade brasileira ganharam corpo e eco. Foram realizadas conferências municipais, estaduais, regionais e temáticas, até a Conferência Nacional e a Conferência Regional das Américas.

Alimentando os debates, o Instituto de Pesquisa Econômica Aplicada (IPEA) sistematizou dados estatísticos sobre a população negra, realizando novas tabulações e análises, dessa vez com os dados de raça e cor desagregados, o que possibilitou o desvelamento estatístico da situação de desigualdade racial existente entre negros e brancos no Brasil. Situação historicamente denunciada pelo movimento negro pela sua vivência "na pele" dos impactos do racismo.

A participação brasileira, do governo e da sociedade civil, em especial de ativistas do movimento negro, foi intensa e significativa tanto no processo de preparação quanto na participação na III Conferência de Durban propriamente dita. O documento oficial levado pelo Brasil refletiu o processo de debate e mobilização social interno desencadeado pelo movimento negro e reforçado pelos dados da pesquisa do IPEA. Foi um momento nacional complexo e rico, ao mesmo tempo.

A Declaração e o Plano de Ação de Durban, resultantes da III Conferência encorajam os Estados signatários a criarem políticas de inclusão sociorracial. Por exemplo, o item 99 do Plano atribui o combate ao racismo e à discriminação racial a "responsabilidade primordial dos Estados" e insta estes a criarem, através de "ações e de estratégias afirmativas ou positivas" (UNFPA, 2001, p. 65) condições necessárias para a efetiva participação de todos na vida social, política, econômica e cultural.

\section{Uma Inflexão Política a Partir dos Anos 2000}

A partir dos anos 2000, o movimento negro intensificou ainda mais o processo de crítica ao modelo de política educacional adotado que não considerava as desigualdades raciais como parte das desigualdades escolares. As ações afirmativas como caminho possível para a diminuição dessa situação, levando a mudanças internas na estrutura do Estado, avançaram como ponto de concordância entre as diferentes organizações do movimento negro e, aos poucos, as entidades se unem no reconhecimento da urgência de implementação 
das cotas raciais como uma modalidade de ação afirmativa para a correção das desigualdades raciais, a curto e médio prazos, no ensino superior.

Com a ascensão do Partido dos Trabalhadores ao governo federal, em 2003, que já havia se comprometido com o avanço institucional da pauta racial em nível de políticas públicas, o Brasil assiste, pela primeira vez, a questão racial ser elevada ao status de política de Estado. A criação da Secretaria de Políticas de Promoção da Igualdade Racial (Seppir), em 2003, é um exemplo dessa mudança.

A Lei $10.639 / 2003$ foi a primeira a ser sancionada pelo governo democrático e popular que se iniciava, como resposta aos movimentos reivindicatórios de décadas sobre o papel e o tratamento da participação africana e afro-brasileira na história e na cultura brasileira e mundial serem conteúdo de ensino obrigatório no Ensino Fundamental e Médio. Logo a seguir, o Conselho Nacional de Educação aprovou o Parecer 03/2004 e a Resolução 01/2004 que ampliaram para todas as etapas e modalidades e explicitaram os fundamentos e caminhos via as Diretrizes Curriculares Nacionais de Educação da Relações Étnico-Raciais. No ano seguinte, 2004, foi criada a Secretaria de Educação Continuada, Alfabetização e Diversidade (Secad) como secretaria no Ministério da Educação cuja proposta era executar uma nova agenda de diversidade e inclusão social e atuar transversalmente nas demais secretarias e nas políticas educacionais. Ao longo dos anos, ampliou sua atuação e os efeitos sobre as políticas educacionais de inclusão social e as específicas de igualdade racial foram significativos.

É importante destacar que o avanço político das ações afirmativas se concretizando em políticas nacionais, regionais e locais, já estava em curso na sociedade brasileira, antes mesmo da criação da Seppir. As cotas raciais, consideradas a mais contundente dessas políticas, já haviam sido aprovadas pela Assembleia Legislativa do Estado do Rio de Janeiro (Alerj), em 2001, pela Lei ${ }^{\circ}$ 3.708/2001, passando a vigorar na Universidade do Estado do Rio de Janeiro (UERJ) e na Universidade Estadual do Norte Fluminense (UENF); foram adotadas também pela Universidade do Estado da Bahia (UNEB), em 2002, por decisão do Conselho Universitário. Cada instituição implementou a medida de acordo com os seus próprios processos, legislação e formas de institucionalização.

A Universidade de Brasília (UnB) é a primeira instituição pública federal de ensino superior aprovar as cotas raciais como critério para ingresso na graduação, em 2004. A partir daí, outras universidades federais tomaram a mesma decisão, mediante votação nos seus conselhos universitários, pressionadas pelo movimento negro, estudantil, técnico-administrativo e docentes favoráveis às ações afirmativas ou via negociação com esses setores.

Um intenso debate foi travado, a partir de então, na sociedade brasileira, envolvendo universidades, institutos de pesquisa, Congresso Nacional, governo, mídias, esfera jurídica, intelectuais, artistas, movimentos sociais e movimento negro, no Brasil, a respeito da constitucionalidade ou não da adoção das ações afirmativas no ensino superior, por meio da modalidade das cotas raciais.

Na realidade, o pano de fundo político de tantas reações consistia em saber qual seria a ação mais eficaz de combate ao racismo por parte do Estado e dos mais diversos setores da sociedade, uma vez que a existência desse fenômeno perverso e estrutural já era reconhecida constitucionalmente em nosso país.

No âmbito das universidades públicas federais, a experiência da UnB torna-se paradigmática pelo fato de ter sua legalidade questionada no Supremo Tribunal Federal (STF), o que levou a mais alta Corte a se manifestar, em 2012, por unanimidade, em favor da constitucionalidade da medida através da Arguição de Descumprimento de Preceito Fundamental.

Em sequência a essa histórica decisão do STF, é sancionada pela então presidenta Dilma Rousseff a Lei 12.711/2012, conhecida também como Lei de Cotas, que dispõe sobre o ingresso nas universidades e institutos federais de ensino técnico de nível médio e superior. Conforme o texto da Lei, 50\% das vagas 
passam a ser preenchidas, por curso e turno, por estudantes oriundos de escola pública; autodeclarados pretos, pardos e indígenas, em proporção no mínimo igual à representação dos grupos na população da unidade da federação em que a instituição se encontra situada (IBGE, 2019); candidatos com renda per capita menor ou igual a um salário mínimo e meio. Em 2016, a Lei no 13.409, altera a Lei de Cotas, para dispor sobre a reserva de vagas para pessoas com deficiência nos cursos técnicos de nível médio e superior das instituições federais de ensino (BRASIL, 2016).

Importante destacar que antes mesmo da aprovação da Lei 12.711/12 no âmbito das instituições de ensino da esfera federal, a Universidade do Estado de Minas Gerais (UEMG) e a Universidade Estadual de Montes Claros, em função da aprovação pela Assembleia Legislativa da Lei Estadual 15.259, de 27 de julho de $2004,{ }^{2}$ adota o sistema de reserva de vaga para os cursos de graduação para afrodescendentes, egressos de escola pública, pessoas com deficiência e indígenas. O Programa de Seleção Socioeconômica da Universidade do Estado de Minas Gerais (Procan) iniciado na UEMG a partir da implementação da referida Lei, estabelece o percentual de vagas reservadas aos grupos sociais acima descritos correspondendo a, no mínimo, 45\% distribuídos conforme percentuais na forma da lei.

O conjunto de iniciativas de ações afirmativas no ensino superior brasileiro ratificado em lei, seja em âmbito estadual, seja na esfera federal, depara-se com os dados sobre a desigualdade de acesso e permanência da população negra no ensino superior que exibiam naquele contexto desafios estruturais a serem superados.

As mudanças advindas da implementação das ações afirmativas, em especial da modalidade de cotas, atingem também o debate e a luta antirracista no campo intelectual com o crescimento do movimento negro de base acadêmica, nos dizeres de RATTS (2011). Em 2000, foi fundada a Associação Brasileira de Pesquisadores Negros (ABPN), responsável pela realização do Congresso Brasileiro de Pesquisadores Negros (Copene). A ABPN surge para congregar pesquisadores negros e não negros que estudam as relações raciais e demais temas de interesse da população negra, produzir conhecimento científico sobre a temática racial e construir academicamente um lugar de reconhecimento das experiências sociais do movimento negro como conhecimentos válidos.

No início do terceiro milênio, uma demanda educacional de ação afirmativa na Educação Básica, reivindicada pelo movimento negro desde os anos de 1980, foi finalmente contemplada. Em 2003, foi sancionada a Lei n. 10.639, alterando os artigos 26-A e 79-B da Lei de Diretrizes e Bases da Educação Nacional (LDB) e tornando obrigatório o ensino de história e cultura afro-brasileira e africana nas escolas públicas e privadas de ensino fundamental e médio. Regulamentada pelo Parecer CNE/CP n. 03/2004 e pela Resolução CNE/CP n. 01/2004, essa Lei foi novamente alterada pela de $\mathrm{n}^{\circ} 11.645 / 08$, com a inclusão da temática indígena.

No momento em que redigimos este artigo, a sociedade brasileira vive outro patamar no que se refere às ações afirmativas. De reivindicação específica do movimento negro, elas se configuram, atualmente, em um conjunto de políticas de promoção da igualdade racial na educação, na saúde e no trabalho.

Mesmo que ainda não sejam fruto de total acordo entre os diferentes setores da sociedade e que algumas delas sejam fruto de implementação irregular pelos estados, municípios e Distrito Federal, elas se tornaram uma realidade em nosso país.

\section{Ações Afirmativas e os Tempos de Retrocessos Democráticos}

No entanto, a partir de 2016, as tensões e disputas entre forças reacionárias, fundamentalistas religiosas e capitalistas (algumas das quais inicialmente constituíram base de apoio ao governo do Partido dos Trabalhadores) por um projeto de Estado e de economia pautado no neoliberalismo e não no Bem-Estar 
Social, resultaram no impeachment que destituiu a presidenta Dilma Rousseff, democraticamente eleita, tomando o poder o seu vice-presidente, considerado pelos grupos da esquerda e pelos movimentos sociais emancipatórios como um dos articuladores desse processo, entendido como golpe parlamentar por vários analistas. De acordo com Bercovici (2016, p. 145):

Não necessitamos de sofismas ou de exercícios retóricos para disfarçar a realidade. Impeachment sem fundamento jurídico nada mais é do que um golpe de Estado. Um golpe patrocinado por parcela do Poder Legislativo, o que não lhe confere legitimidade alguma. Não interessa de onde se origina, podendo ser proveniente do Poder Legislativo, de um tribunal, palácio ou quartel, tampouco interessa a denominação que se queira dar, a natureza das coisas não muda: golpe é golpe.

Esse processo abriu espaço para o empoderamento de outras forças conservadoras e reacionárias levando ao poder executivo federal um governo de extrema direita. A gestão federal passou a se configurar em um projeto de negação de direitos sociais conquistados pela sociedade brasileira, principalmente pelos trabalhadores e pelas trabalhadoras. Além disso, as pautas dos movimentos sociais em prol do reconhecimento e do direito à diversidade, muitas das quais haviam se transformado em políticas públicas e programas de governo no período de 2003 ao início de 2016 perderam força. Outras foram destituídas e outro grupo tem sido descaracterizado.

É nesse contexto que se encontra a Seppir, que perdeu o status de ministério e se transformou em uma das instâncias do atual Ministério da Mulher, da Família e dos Direitos Humanos (MMFDH). O Ministério da Cultura foi extinto e a Fundação Cultural Palmares passou a ser gerida por um presidente e equipe gestora contrários aos seus próprios objetivos.

Esse procedimento reacionário do atual presidente da Fundação Palmares tem sido motivo de ações na justiça da parte de organizações do movimento negro e, inclusive, de funcionários da própria instituição com relação às práticas autoritárias desse gestor (NOVO... 2020).

Ao citar as falas de Sérgio Camargo, presidente da Fundação Palmares do governo do presidente Jair Bolsonaro, ${ }^{3}$ SANTOS (2020) argumenta que o discurso dos gestores sob o comando do chefe do executivo federal pode ser compreendido como a manifestação epidérmica de processos que têm, como pano de fundo, a ascensão de grupos e coalizões de poder que têm na desconstrução da pauta étnico-racial um elemento central de seus projetos de sociedade, de nação e de território.

É estarrecedor que um gestor público se manifeste nas redes sociais com afirmações desrespeitosas, tais como:

O movimento negro, os vagabundos do movimento negro, essa escória maldita.

Não tenho que admirar Zumbi dos Palmares, que pra mim era um filho da puta que escravizava pretos. Não tenho que apoiar Dia da Consciência Negra. Aqui não vai ter, zero - aqui vai ser zero pra [Dia da] Consciência Negra. (SANTOS, 2020, p. 201)

Nesse contexto de retrocessos, as universidades públicas vivem um processo de ataques à ciência, desrespeitos às consultas para reitores e reitoras, retirada de recursos orçamentários, enfraquecimento da política de assistência estudantil e discursos negacionistas oriundos do próprio governo e do Ministério da Educação. As escolas de Educação Básica públicas também sofrem uma série de ataques com a diminuição do orçamento, fiscalização ideológica da ação de educadoras e educadores críticos às desigualdades na sociedade e ao próprio governo federal.

São tempos difíceis para a continuidade das ações afirmativas como políticas. Tempos de renovação 
e reorientação das lutas por direitos e pelo direito à educação. É também nesse contexto que, no ano de 2022, serão revistas, de acordo com o artigo $7^{\circ}$ da referida lei.

Art. $7^{\circ}$ No prazo de dez anos a contar da data de publicação desta Lei, será promovida a revisão do programa especial para o acesso às instituições de educação superior de estudantes pretos, pardos e indígenas e de pessoas com deficiência, bem como daqueles que tenham cursado integralmente o ensino médio em escolas públicas. (BRASIL, 2016)

O processo de revisão da Lei 12.711/12 a ser realizado pelo Ministério da Educação e pela Seppir, em um momento pós-pandemia marcado pelo aumento da pobreza, das desigualdades sociais, de explicitação do racismo, do machismo e da LGBTfobia em nosso país é preocupante. ${ }^{4}$

É também motivo de preocupação a forma como setores conservadores e reacionários do Congresso Nacional têm oportunisticamente se aproveitado desse momento que antecede a revisão e apresentado mais de uma dezena de projetos de lei que descaracterizam a Lei 12.711, principalmente no que se refere ao critério racial. No campo progressista do Parlamento também assistimos projetos que defendem a continuidade da mesma Lei e entendem o momento de revisão como possibilidade de avaliação e de continuidade e não de retrocessos. As tensões em torno da Lei de Cotas expressam como estamos em um momento em que se percebe uma correlação desigual de forças no Congresso Nacional entre os setores progressistas e conservadores.

Essa realidade de retrocessos às pautas e ao clima democrático que possibilitava a existência e o apoio às políticas de igualdade racial da parte do governo federal é comprovada no estudo "Um país sufocado - Balanço do Orçamento Geral da União 2020", publicado no dia 04/04/21 pelo Instituto de Estudos Socioeconômicos (INESC, 2020): as políticas públicas específicas para comunidades quilombolas ou de igualdade racial no Plano Plurianual (PPA) 2020-2023 inexistem. Mesmo assim, a Seppir continua a figurar no MMFDH, assim como o Conselho Nacional de Promoção da Igualdade Racial (CNPIR) e o Conselho Nacional dos Povos e Comunidades Tradicionais (CNPCT). Na realidade são órgãos que não mais representam os coletivos sociais e raciais para os quais foram criados em tempos democráticos.

O estudo ainda aponta que o Governo Bolsonaro extinguiu o Programa 2034: Promoção da Igualdade Racial e Superação do Racismo, que não recebeu nenhum real em 2020. Em 2019, tinha recebido 10,3 milhões. O MMFDH chegou ao final do ano passado deixando de gastar $70 \%$ do recurso autorizado. Dos 120,4 milhões reais, usou 35,4 milhões.

\section{Lições da Implementação das Cotas como Política de Igualdade Racial, no Brasil}

Diante do exposto, podemos afirmar que o momento atual de desmonte do Estado Democrático e de Direito vivido pelo Brasil, das políticas públicas sociais e, dentre elas, as ações afirmativas, configura-se simbólica e politicamente como um dos ataques mais concretos à implementação das políticas de igualdade racial em nosso país.

Tais ataques são perpetrados não somente porque tais políticas se voltam para a maior democratização do acesso e da permanência de grupos historicamente excluídos do ensino superior público federal, mas também porque as políticas de ações afirmativas explicitam a crítica aos privilégios sociais, econômicos e raciais arraigados em nossa estrutura social e explicitam a existência do racismo estrutural e epistêmico.

Ao promoverem esse deslocamento, as ações afirmativas na modalidade cotas abrem caminhos para a indagação, desvelando ainda mais a existência da colonialidade do saber. Democratizar o acesso de negros, estudantes pobres, indígenas, pessoas com deficiência no ensino superior é também possibilitar a 
formação de quadros profissionais, intelectuais, políticos, artísticos diversos na disputa por lugares de direito à diversidade no mercado de trabalho.

Por isso as cotas, embora não sejam sinônimo de ações afirmativas, dado que são uma das suas modalidades de implementação, assumem um caráter político primordial na luta por direito à igualdade racial e à diversidade não só no ensino superior, mas também na sociedade de um modo geral.

Nesse processo, a revisão da Lei 12.711/12 em curso só pode ser uma: a sua continuidade. Essa continuidade é o ponto comum entre as entidades do movimento negro e de todos os setores que lutam pelo direito ao ensino superior. As lutas desencadeadas pelo movimento negro ao longo de sua história, que tiveram alguns momentos referenciados neste texto, renovam-se no tempo presente a partir da atuação dos coletivos de estudantes negros presentes em diversas universidades públicas brasileiras. Ao se apresentarem como herdeiros de lutas históricas a reivindicarem o direito ao acesso e à permanência bem-sucedida da população negra nas fileiras do ensino superior, os coletivos emergem na cena pública também como resultado das políticas de ações afirmativas em curso no ensino superior. De acordo com Guimarães, Rios e Sotero (2020, p. 309), esses coletivos "procuram agenciar, formar e organizar politicamente estudantes negros e cotistas, além de acompanhar a implementação das políticas de ações afirmativas e apoiar a carreira universitária estudantil".

Finalizando, é possível dizer que a inflexão trazida pela adoção das cotas como modalidade radical e mais democrática de ação afirmativa tem nos reeducado. Por meio delas, o Estado, a sociedade brasileira e aquelas e aqueles que lutam pela retomada democrática do nosso país têm aprendido algumas lições. Destacaremos algumas delas:

- Primeira: as cotas fazem parte de uma luta corajosa do movimento negro por igualdade racial e equidade no ensino superior que se expandiu e foi compreendida por outros setores da sociedade. É por isso que a Lei abrange escola pública, indígenas e pessoas com deficiência.

- Segunda: Com todos os limites, problemas e discussões não se pode negar que as ações afirmativas na modalidade cotas trouxeram às instituições públicas de ensino superior que as adotaram — estaduais e federais - o alargamento da nossa defesa pela dimensão pública do ensino superior.

- Terceira: As ações afirmativas, em especial a modalidade cotas, aperfeiçoam a nossa luta pela democracia. Elas colocam em destaque a indagação de que qualquer instituição pública brasileira que não retrate de forma igualitária e equânime a diversidade socioeconômica, étnica, racial e de gênero existente em nosso país não cumpre com a sua missão pública. Acaba privilegiando segmentos sociais e étnico-raciais que já têm um histórico de privilégios em nosso país e reproduz a elitização social e racial da ciência e do conhecimento contra a qual aquelas e aqueles que defendem a democratização da própria ciência e do próprio conhecimento lutam historicamente.

- Quarta: a adoção da Lei 12.711/12 visibilizou ainda mais nas instituições públicas de ensino superior uma produção epistemológica que deu nova vida e ânimo à extensão, ao ensino, à pesquisa e à internacionalização. Vários conceitos e categorias analíticas com os quais estamos comodamente acostumados a trabalhar têm sido indagados pela juventude negra, periférica, quilombola, do campo, indígena, trans que chegou por direito ao ensino superior, trazendo a sua corporeidade, sua experiência estética, outros conceitos, outros autores e autoras, outras indagações advindas das suas experiências sociais. Isso tem feito a universidade repensar a sua relação com o conhecimento.

- Quinta: A implementação da Lei 12.711/12 tem aprimorado o debate sobre assistência estudantil como um direito dos estudantes e dever do MEC e das instituições federais de ensino superior. A continuidade da Lei de Cotas exige, também, recursos dignos e urgentes para a assistência estudantil 
que é uma das formas de garantia das condições materiais de permanência dos estudantes cotistas.

- Sexta: A superação do racismo e de outras formas de preconceito e de discriminação existentes em nossa sociedade não será alcançada se apenas a educação a ela se dedicar. É necessário, portanto, que outros campos da vida social - a cultura, a vida política, os esportes, o mundo do trabalho participem desse compromisso para que a educação não seja isolada como política pública redentora e que assim, agravem-se os riscos de um fracasso indesejado por todos.

A implementação das ações afirmativas de promoção da igualdade racial ressignificou a luta pelo direito à educação no Brasil. A entrada de sujeitos pertencentes a coletivos diversos e historicamente tratados como desiguais no ensino superior público e, principalmente, nas universidades públicas federais, a presença de pessoas negras nos concursos públicos da administração federal por meio da implementação das cotas raciais em decorrência da Lei 12.990/14, as várias iniciativas de ensino de história e cultura afro-brasileira e africana nas escolas da Educação Básica, bem como os direitos garantidos no Estatuto da Igualdade Racial, têm feito emergir diversos conhecimentos e experiências produzidos pelos sujeitos negros nas suas vivências comunitárias, políticas, sociais, culturais, artísticas, nas suas histórias ancestrais, na sua sobrevivência frente a tantas desigualdades e violências. E isso tem transformado a ciência, a educação e a sociedade.

Por tudo isso, não podemos retroceder. As ações afirmativas como políticas de promoção da igualdade racial na educação representam uma das maiores inflexões democráticas na educação brasileira dos últimos 20 anos.

\section{Contribuição dos Autores}

Problematização e Conceituação: Gomes NL; Metodologia: Silva PV; Análise: Gomes NL, Brito JE, Silva PV.

\section{Notas}

1. De acordo com Moehlecke (2002, p. 199): “Mas a ação afirmativa não ficou restrita aos Estados Unidos. Experiências semelhantes ocorreram em vários países da Europa Ocidental, na Índia, Malásia, Austrália, Canadá, Nigéria, África do Sul, Argentina, Cuba, dentre outros. Na Europa, as primeiras orientações nessa direção foram elaboradas em 1976, utilizando-se freqüentemente a expressão 'ação ou discriminação positiva'. Em 1982, a 'discriminação positiva' foi inserida no primeiro 'Programa de Ação para a Igualdade de Oportunidades' da Comunidade Econômica Européia”.

2. Em 2017, essa lei foi revogada e substituída pela Lei Estadual 22.570/2017, que eleva o percentual de reserva de vagas para 50\% para as universidades estaduais de Minas Gerais - UEMG e Unimontes, e institui a política de assistência estudantil.

3. O elogio de Bolsonaro às declarações do presidente da Fundação Palmares pode ser acessado em Redação Jornal de Brasília (2019).

4. Art. $6^{\circ} \mathrm{O}$ Ministério da Educação e a Secretaria Especial de Políticas de Promoção da Igualdade Racial, da Presidência da República, serão responsáveis pelo acompanhamento e avaliação do programa de que trata esta Lei, ouvida a Fundação Nacional do Índio (Funai) (BRASIL, 2016). 


\section{Referências}

BERCOVICI, G. O golpe do impeachment. In: PRONER, C. et al. A resistência ao golpe de 2016. Bauru: Canal 6, 2016. P. 141-145.

UNFPA - United Nations Population Fund. Conferência mundial contra o racismo, discriminação racial, xenofobia e intolerância correlata. Brasília: [s.n.], 2001. Disponível em: http://www.unfpa.org.br/Arquivos/ declaracao_durban.pdf. Acesso em: 19 nov. 2021.

BRASIL. Lei n. 7.668, de 22 de agosto de 1988. Autoriza o Poder Executivo a constituir a Fundação Cultural Palmares - FCP, e dá outras providências. Diário Oficial da União: Brasília, 1988. Disponível em: http:// www.planalto.gov.br/ccivil_03/leis/17668.htm. Acesso em: 11 nov. 2021.

BRASIL. Lei n. 12.711, de 29 de agosto de 2012. Dispõe sobre o ingresso nas universidades federais e nas instituições federais de ensino técnico de nível médio e dá outras providências. Diário Oficial da União: Brasília, 2012. Disponível em: http://www.planalto.gov.br/ccivil_03/_ato2011-2014/2012/lei/112711.htm. Acesso em: 11 nov. 2021.

BRASIL. Lei n. 13.409 de 28 de dezembro de 2016. Altera a Lei no 12.711, de 29 de agosto de 2012, para dispor sobre a reserva de vagas para pessoas com deficiência nos cursos técnico de nível médio e superior das instituições federais de ensino. Diário Oficial da União: Brasília, 2016. Disponível em: http://www.planalto. gov.br/ccivil_03/_ato2015-2018/2016/lei/113409.htm. Acesso em: 11 nov. 2021.

BRITO, J. E. Política educacional: a questão racial e as desigualdades sociais no Brasil. Paidéia, Belo Horizonte, ano VIII, n. 11, p. 113-125, 2011. Disponível em: http://revista.fumec.br/index.php/paideia/article/view/1312. Acesso em: 1 out. 2021.

DOMINGUES, P. Ações afirmativas para negros no Brasil: o início de uma reparação histórica. Revista Brasileira de Educação, Rio de Janeiro, n. 29 p. 164-176, 2005. https://doi.org/10.1590/S1413-24782005000200013

DOMINGUES, P. Movimento negro brasileiro: alguns apontamentos históricos. Tempo, Niterói, v. 12, n. 23 , p. 100-122, 2007. https://doi.org/10.1590/S1413-77042007000200007

DOMINGUES, P. Um “templo de luz": Frente Negra Brasileira (1931-1937) e a questão da educação. Revista Brasileira de Educação, Rio de Janeiro, v. 13, n. 39, p. 517-534, 2008. https://doi.org/10.1590/ S1413-24782008000300008

GOMES, N. L. O movimento negro educador: Saberes construídos naslutas por emancipação. Petrópolis: Vozes, 2017.

GUIMARÃES, A. S. A.; RIOS, F.; SOTERO, E. Coletivos negros e novas identidades raciais. Novos estudos CEBRAP, São Paulo, v. 39, n. 2, p. 309-327, 2020. https://doi.org/10.25091/s01013300202000020004

IBGE [INSTITUTO BRASILEIRO DE GEOGRAFIA E ESTATÍSTICA]. Desigualdades sociais por cor ou raça no Brasil. Estudos e Pesquisas, Informação Demográfica e Socioeconômica, Brasília: IBGE, n.41, 2019. Disponível em: https://biblioteca.ibge.gov.br/visualizacao/livros/liv101681_informativo.pdf. Acesso em 19 nov. 2021.

INESC [INSTITUTO DE ESTUDOS SOCIOECONÔMICOS]. Um país sufocado - Balanço do Orçamento Geral da União 2020. Brasília: INESC, 2020. Disponível em: https://www.inesc.org.br/umpaissufocado/. Acesso em: 12 nov. 2021. 
LIMA, I. C. Trajetos históricos das pedagogias promovidas pelo movimento negro no Brasil. In: NOGUEIRA, J. C.; PASSOS, J. C. dos; SILVA, V. B. M. da (Eds.). Negros no Brasil: política, cultura e pedagogias. Florianópolis: Atilènde, 2010. p. 3-63.

MARÇAL, J. A. Políticas afirmativas para negros nas universidades federais entre 2002 e 2012: processos e sentidos na UNB, UFPR e UFBA. 2016. Tese (Doutorado em Educação) - Universidade Federal do Paraná, Curitiba, 2016.

MOEHLECKE, S. Ação afirmativa: História e debates no Brasil. Cadernos de Pesquisa, São Paulo, n. 117, p. 197-217, 2002. https://doi.org/10.1590/S0100-15742002000300011

NASCIMENTO, A. Quilombo: vida, problemas e aspirações do Negro. São Paulo: Editora 34, 2003.

NOVO presidente da Fundação Palmares nega a existência do racismo no Brasil. Globonews, 2020. Disponível em: https://g1.globo.com/globonews/jornal-globonews-edicao-das-18/video/novo-presidente-da-fundacaopalmares-nega-a-existencia-do-racismo-no-brasil-8124954.ghtml. Acesso em: 8 nov. 2021.

PEREIRA, A. M. Trajetórias e perspectivas do movimento negro brasileiro. Belo Horizonte: Nandyala, 2008.

PINHO, O. de A. "O sol da liberdade”: movimento negro e a crítica das representações raciais. Com Ciência, 2003. Disponível em: https://www.comciencia.br/dossies-1-72/reportagens/negros/15.shtml. Acesso em: 10 out. 2021.

RATTS, A. Corpos negros educados: notas acerca do movimento negro de base acadêmica. NGUZU: revista do Núcleo de Estudos Afro-Asiáticos, Londrina, v. 1, p. 28-39, 2011.

REDAÇÃO JORNAL DE BRASÍLIA. Bolsonaro elogia declaração do novo presidente da Fundação Palmares. Jornal de Brasília, 2019. Disponível em: https://jornaldebrasilia.com.br/noticias/politica-e-poder/bolsonaroelogia-declaracao-do-novo-presidente-da-fundacao-palmares/. Acesso em: 20 out. 2021.

SANTOS, R. E. N. A questão racial e as políticas de promoção da igualdade em tempos de golpe: inflexão democrática, projetos de nação, políticas de reconhecimento e território. Caderno Prudentino de Geografia, Presidente Prudente, v. 4, n. 42, p. 200-224, 2020. Disponível em: https://revista.fct.unesp.br/index.php/cpg/ article/view/7877. Acesso em: 11 nov. 2021.

SILVA, P. V. B.; BORBA, C. A. Políticas Afirmativas na Pesquisa Educacional. Educar em Revista, Curitiba, v. 34, n. 69, p. 151-191, 2018. https://doi.org/10.1590/0104-4060.58095

SILVÉRIO, V. R. Ação afirmativa e o combate ao racismo institucional no Brasil. Cadernos de Pesquisa, São Paulo, n. 117, p. 219-246, 2002. https://doi.org/10.1590/S0100-15742002000300012

\section{Sobre os autores}

Nilma Lino Gomes é doutora em Antropologia Social/USP, pós-doutora em Sociologia pela Universidade de Coimbra/Portugal e em Educação pela Universidade Federal de São Carlos (UFSCar), Brasil. É professora titular emérita da Faculdade de Educação da Universidade Federal de Minas Gerais (UFMG), Brasil. Bolsista de Produtividade em Pesquisa/CNPq. Coordenadora do Núcleo de Estudos e Pesquisas sobre Relações 
Étnico-Raciais e Ações Afirmativas (NERA/CNPq). Professora do Programa de Pós-Graduação em Educação Conhecimento e Inclusão Social da FAE/UFMG. Integra o quadro de pesquisadores da Associação Brasileira de Pesquisadores Negros (ABPN) e da Associação Nacional de Pós-Graduação e Pesquisa em Educação (Anped). Foi reitora pró-tempore da Universidade Internacional da Lusofonia Afro-brasileira (UNILAB), Brasil, no período de 2013 e 2014.

Paulo Vinicius Baptista da Silva é doutor em Psicologia Social pela Pontifícia Universidade Católica de São Paulo (PUC/SP). Pós-doutor em Análise Crítica do Discurso na Universidade Pompeu Fabra (Barcelona/ Espanha). É professor da Universidade Federal do Paraná (UFPR), onde atua no Programa de Pós-Graduação em Educação (PPGE-UFPR). Bolsista de Produtividade Científica do CNPq. Pesquisador do Núcleo de Estudos Afro-Brasileiros (NEAB-UFPR). É superintendente da Superintendência de Inclusão, Políticas Afirmativas e Diversidade da UFPR (Sipad). Integra o quadro de pesquisadores da Associação Brasileira de Pesquisadores Negros (ABPN) e da Associação Nacional de Pós-Graduação e Pesquisa em Educação (Anped).

José Eustáquio de Brito é doutor em Educação pela Universidade do Estado de Minas Gerais (UEMG). Integra o quadro de pesquisadores do Núcleo de Estudos e Pesquisas sobre Educação e Relações ÉtnicoRaciais (NEPER) da Faculdade de Educação da Universidade do Estado de Minas Gerais (FaE-UEMG), Brasil. Docente do Programa de Pós-Graduação stricto sensu "Educação e Formação Humana", da FaEUEMG e professor colaborador do Programa de Mestrado Profissional em Segurança Pública e Cidadania, da Faculdade de Políticas Públicas da UEMG. Integra o quadro de pesquisadores da Associação Brasileira de Pesquisadores Negros (ABPN) e da Associação Nacional de Pós-Graduação e Pesquisa em Educação (Anped). Foi vice-reitor da Universidade do Estado de Minas Gerais (UEMG), Brasil, gestão 2014-2018.

Recebido: 13 nov. 2021

Aceito: 15 nov. 2021 